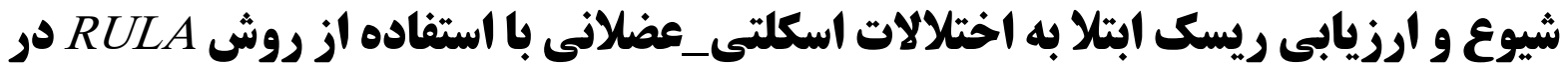

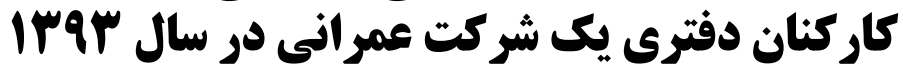

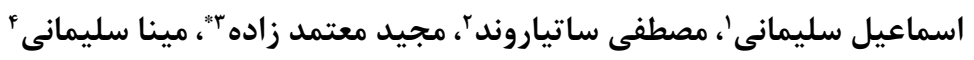 \\ ا. دانشجوى دكترى، مركز يزوهش دانشجويان، كروه بهداشت حرفه اى، دانشكده بهداشت، دانشكاه علوم يزشكى همدان، همدان، ايران

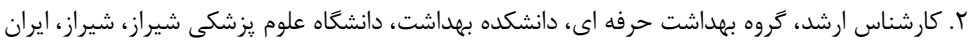

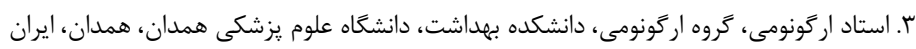

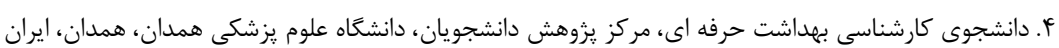

\section{OMr}

مقدمه: اختلالات اسكلتى_عضلانى از مشكلات عمده در محيط هاى كارى بوده كه سبب از دست رفتن

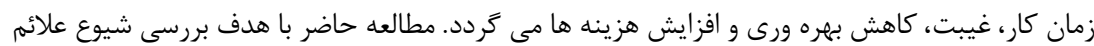

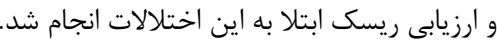

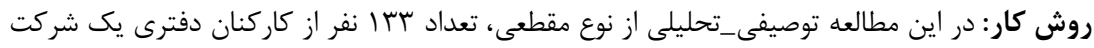

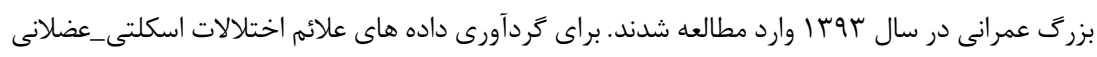

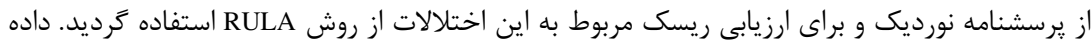

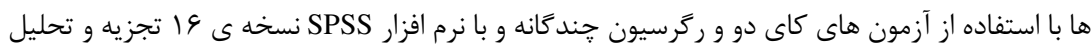
شدند.

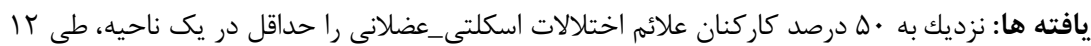

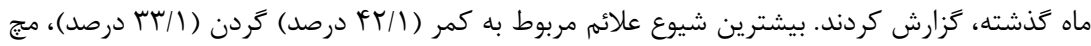

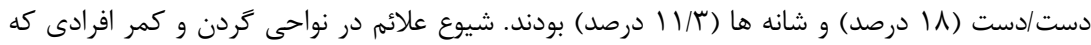

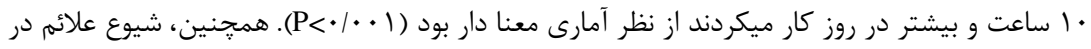

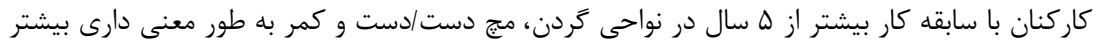

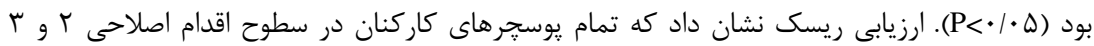
قرار دارند. نتيجه كَيرى: يافته ها نشان داد علائم اختلالات اسكلتى_عضلانى در كاركنان دفترى شيوع بالايى دارد و سطح ريسك اين اختلالات متوسط به بالا است. همجنين، عوامل تاثير كذار اصلى در شيوع اين علائم

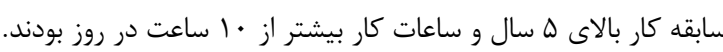

\section{مشخصات مقاله}

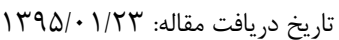

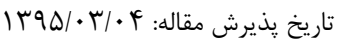

\section{G}

اختلالات اسكلتى_عضلانى

شيوع

RULA كاركنان دفترى

فويسنله مسئرل

مجيد معتمدزاده، استاد، كروه اركونومى، دانئ

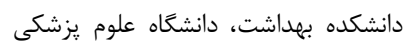

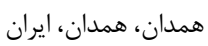

تلفن: ايميل: Motamedzade@Umsha.ac.ir

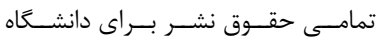

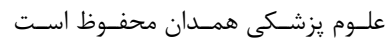

دسته بندى مى شوند [[]]. سن، طول قد و اعتياد به سيگار مى توانند در بروز اختلالات اسكلتى عضلانى نقش داشته باشند

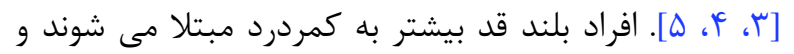

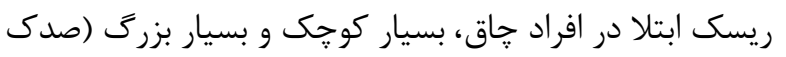

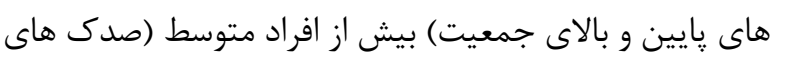

بر اساس تعريف اختلالات اسكلتى_عضلانى شامل اختلالات ماهيجه ها، استخوان ها، مفاصل، اعصاب و عروق خونى مى باشد [1] اين اختلالات جند علتى بوده عوامل ايجاد كننده آنها به طور كلى در تجهار گروه شامل عوامل مورفولوزيك، عوامل زنتيكى، عوامل بيومكانيكى و عوامل روانى_اجتماعى 
مج دست/دست (• ب درصد) و شانه ها (ع اعرصد) بودند. در كاربران رايانه نيز V\& درصد كاربران احساس درد و ناراحتى را گزارش كرده اند [IV] نتايج مشابهى نيز توسط محققين ديگر

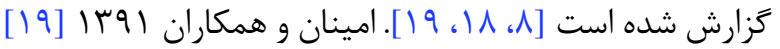
كزارش كرده اند كه VD درصد كاركنان دفترى از اختلالات اسكلتى_عضلانى رنج مى برند و بيشترين نواحى درگير به

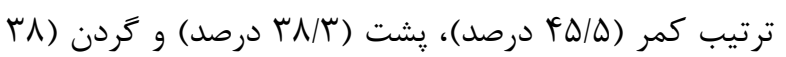
درصد) بودند. همجنين جوبينه و همكاران | وسا در مطالعه ايى

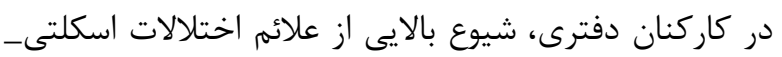
عضلانى، غيبت از كار و مراجعه كاركنان به مراكز درمانى به

دليل اين اختلالات راكزارش كرده اند [9]. با توجه به موارد بالا، و اينكه ماهيت كارهاى دفترى به گونه اى است كه كاركنان را در معرض ريسك ابتلا به اختلالاتاسكلتى_عضلانى قرار مى دهد، مطالعه حاضر با هدف بررسى كا. شيوع علائم اختلالات اسكلتى_عضلانى و ارزيابى ريسك ابتلا به اين اختلالات در كاركنان دفترى يك شركت بزرى عمرانى

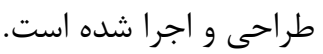

\section{روش كار}

اين مطالعه توصيفى_تحليل از نوع مقطعى در يك شركت بزرى عمرانى در سال سوس | انجام شد. تمامى :رسنل شاغل در شركت مرد بوده و همه آنها (وץ| نفر) شامل كاركنان دفترى و فنى_ مهندسى با حداقل يك سال سابقه كار در حرفه موردنظر در مطالعه شركت داده شدند. افرادى كه در اثر حوادث و بيمارى هاى زمينه اى دجار آسيب هاى اسكلتى_عضلانى شده بودند

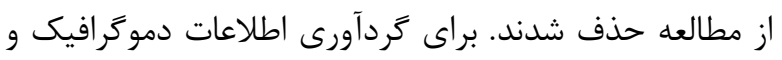
داده هاى مربوط به شيوع علائم اختلالات اسكلتى_عضلانى از يرسشنامه استفاده شد. يرسشنامه شماره يك شامل يرسش هايى در رابطه با ويزگى هاى فردى (شامل سن، طول قد، وزن، و وضعيت تاهل)، سابقه كار، متوسط ساعات كار در روز، سابقه حادثه و بيمارى هايى كه روى سيستم اسكلتى_عضلانى تاثير كذار هستند، مراجعه به :زشك و غيبت از كار به دليل علائم اختلالات اسكلتى_عضلانى، آشنايى با ارگونومى و ورزش كردن است. براى بررسى شيوع علائم اختلالات اسكلتى_عضلانى
ميانى جمعيت) است [9]. در صورتى كه محيط كار در ايجاد اين اختلالات نقش داشته باشد اين اختلالات مرتبط با كار دانسته مى شوند. در واقع محيط كار نقش عمده اى در شيوع بسيارى از مشكلات اسكلتى_عضلانى دارد، هر جند بسيارى از اين مسائل را مى توان با رعايت و توجه بيشتر به اصول

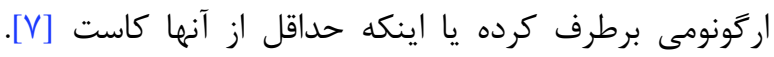
امروزه اختلالات اسكلتى عضلانى يكى از عوامل شايع آسيب برطب ها و ناتوانى ها در كشورهاى صنعتى و در حال توسعه به شمار مى رود. اين اختلالات از مشكلات عمده در محيط هاى كارى بوده كه سبب از دست رفتن زمان كار، غيبت از كار، كاهش بهره ورى كاركنان و افزايش هزينه هاى توليد و خدمات مى گردد [A] و بنابراين يكى از دغدغه هاى اصلى مديران صنايع مى باشد. برخى عوامل خطر منتسب به محيط كار كه در وقوع اين اختلالات نقش دارند شامل يوسجر نامطلوب، كار استاتيك، عوامل محيطى (مثل سرما) وعوامل روانى مى باشند [9]. انجام كارهاى استاتيك, تكرارى و طولانى مدت به همراه اتخاذ يوسجرهاى نامناسب، به دليل غير ارگونوميك بودن ايستغاه هاى كار (ميز و صندلى) در ادارات، حين كارهاى دفترى و يا استفاده طولانى مدت از رايانه كه امروزه جزء جدايى نايذير محيط هاى كار ادارى است سبب احساس درد، ناراحتى و بى حسى در نواحى گوناگون سيستم اسكلتى_عضلانى مى گردد

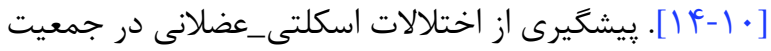
هاى كارى نيازمند ارزيابى فاكتورهاى ويزه شغلى، ويزگى -هاى فردى و تعيين ارتباط ميان آنها با اين اختلالات مى باشد به كونه اى كه اصلاح ريسك فاكتورهاى نواحى گوناگون بدن مى تواند از گسترش درد و ناراحتى در اين نواحى جلوگيرى كند [1 [10]. با توجه به اهميت اختلالات اسكلتى_عضلانى و تاثير منفى آن در توليد، بهره ورى، كيفيت زندگى و هزينه هاى درمانى مطالعاتى در اين خصوص در ادارات و صنايع گَناگون در داخل و خارج كشور انجام گرفته است. جانوانتاكول و همكاران

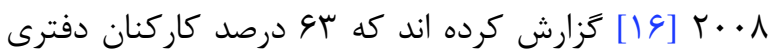
احساس درد و ناراحتى را حداقل در يك ناحيه از سيستم اسكلتى_عضلانى اعلام كرده اند و شايع ترين نواحى درگير به

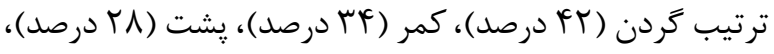


در نواحى گوناتون بدن در طول يكسال كذشته از يرسشنامه يافته ها از 9"1 إرسنل مورد مطالعه، 9 نفر معيارهاى ورود به مطالعه را نداشتند و از مطالعه حذف شدند. ويزگى هاى دموكرافيك

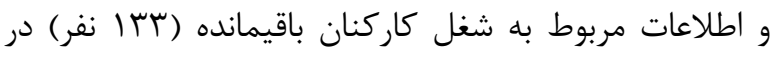
جدول شماره ا ارائه شده است. همانكونه كه ملاحظه مى بـ شود، جمعيت مورد مطالعه كاركنان جوانى (ميانكين سن افراد

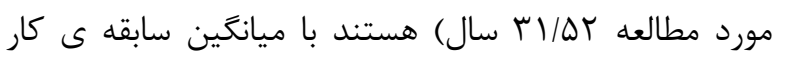

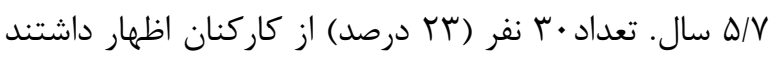

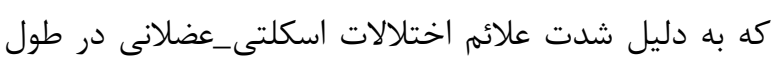

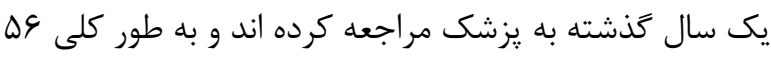

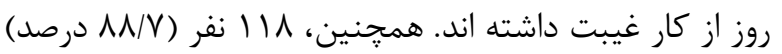

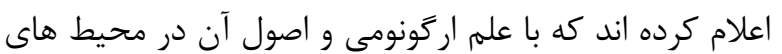

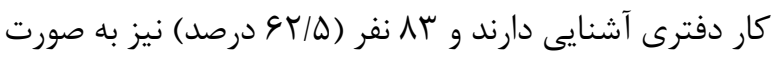

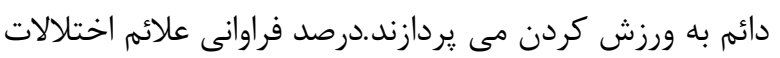

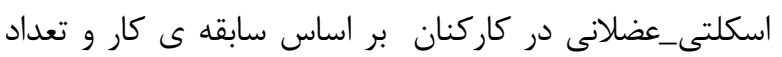

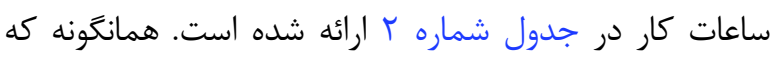
ملاحضه مى شود، بيشترين شيوع علائم به ترتيب مربوط به دراته

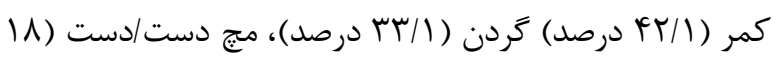

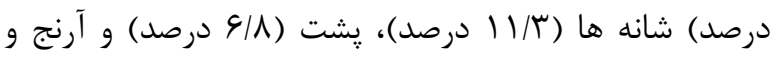

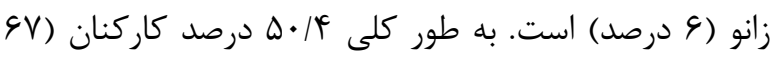

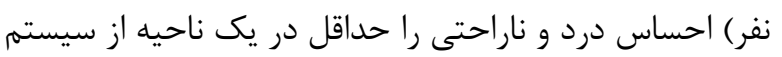

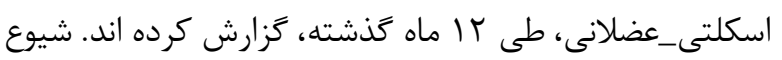

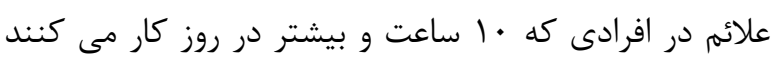

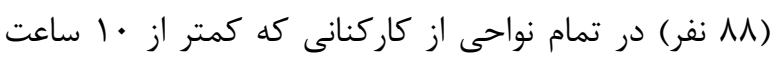

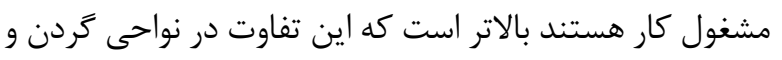

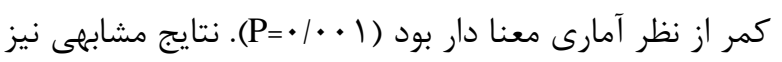

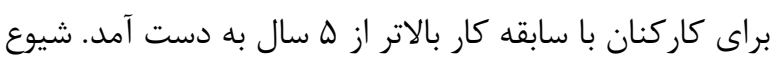

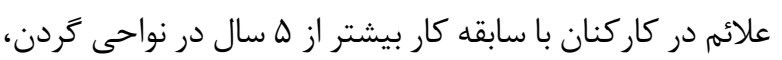

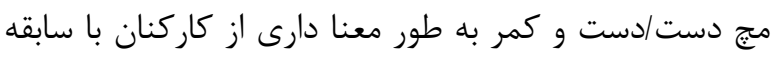

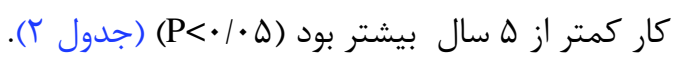

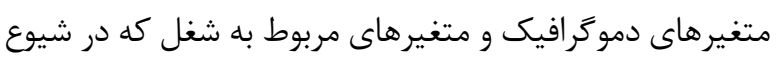

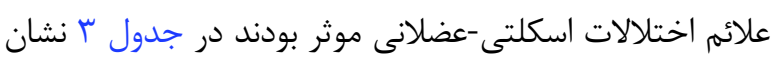

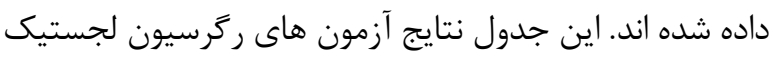

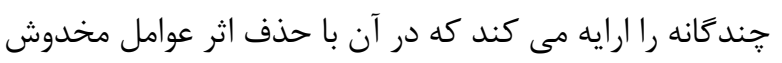

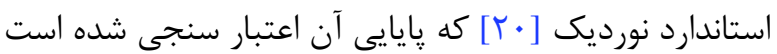

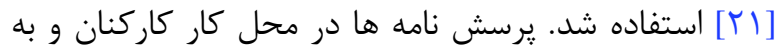
صورت جهره به جهره تكميل مى شدند. در اين مطالعه منظور از علائم اختلالات اسكلتى_عضلانى احساس درد، خستكى،

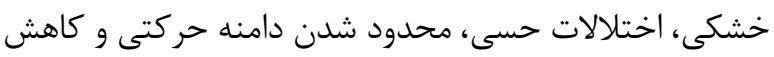

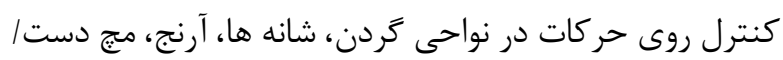

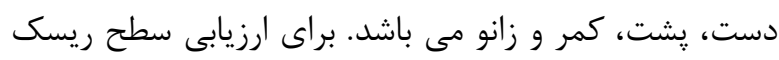

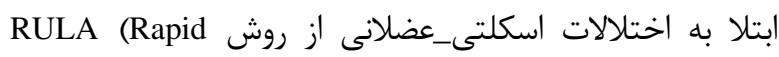

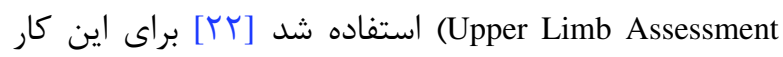
از يوسجرهاى كاركنان در حين كار عكسبردارى صورت مى نى

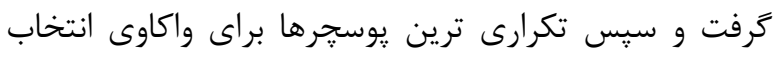
مى شد. امتيازهاى A و B به ترتيب براى ارزيابى اثر تركيبى لرئ

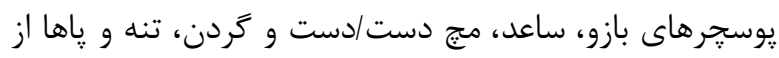
جداول مربوط به روش RULA استخراج مى شد. سيس امتياز

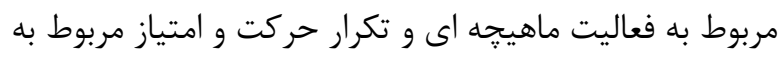

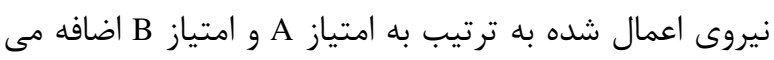

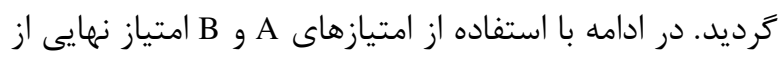
جدول مربوطه استخراج مى شد و سرانجام با توجه به امتياز نهايى، سطح اولويت اقدام هاى اصلاحى (Action level) تعيين مى كرديد. به دليل مشابه بودن شرايط كار و ايستكاه هاى كار در مشاغل دفترى و نيز عدم همكارى برخى از كاركنان در

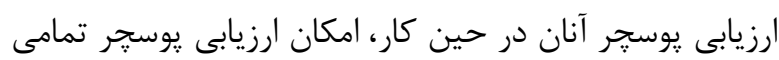

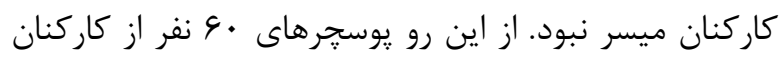
مورد واكاوى قرار كرفت.

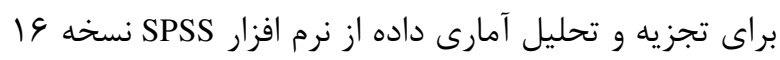

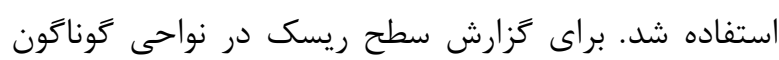
بدن از آمار توصيفى و براى بررسى رابطه علائم اختلالات اسكلتى_عضلانى با متغيرهاى مورد بررسى از آزمون كاى آى اسكوئر استفاده شد. همجنين به منظور تعيين اثر متغيرهاى دموكرافيك و متغيرهاى مربوط به شرايط كار با حذف اثر انر اندين عوامل مخدوش كننده از آزمون ركرسيون خند آندانه استفاده

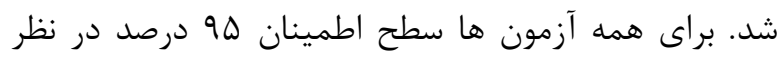
كرفته شد. 


\begin{tabular}{|c|c|c|c|c|}
\hline بيشترين & كمترين & انحراف معيار & ميانغين & متغير \\
\hline$\Delta \Lambda$ & $r \cdot$ & V & TI/DT & سن (سال) \\
\hline 191 & 19. & 4 & IVD & طول قد (سانتى متر ) \\
\hline 11. & $\Delta \Delta$ & $1 \cdot / V$ & $V V / r$ & وزن (كيلوكرم) \\
\hline rq & $I V / \Delta$ & $r / V$ & $r \Delta / T H$ & شاخص توده بدنى (BMI) \\
\hline$r$. & 1 & $\Delta / \Delta$ & $\Delta / V$ & سابقه كار (سال) \\
\hline \multirow[t]{8}{*}{14} & $\Delta$ & $1 / V$ & $9 / 1$ & تعداد ساعات كار در روز \\
\hline & & درصد & ت عداد & \\
\hline & & $V T / T$ & 94 & متاهل \\
\hline & & $r V / \Lambda$ & rv & وضعيت تاهل \\
\hline & & Tr/G & $r \cdot$ & مراجعه به يزشك \\
\hline & & - & $\Delta \varphi$ & روزهاى غيبت از كار \\
\hline & & $\Lambda \Lambda / V$ & 111 & آشنايى با ارتونومى \\
\hline & & $G T / F$ & N & ورزش كردن \\
\hline
\end{tabular}

جدول r. درصد فراوانى علائم اختلالات اسكلتى_عضلانى در كاركنان بر اساس سابقه كار و تعداد ساعات كار در روز (سب IN)

\begin{tabular}{|c|c|c|c|c|c|c|c|}
\hline \multicolumn{4}{|c|}{ سابقه كار } & \multicolumn{3}{|c|}{ تعداد ساعات كار در روز } & \multirow[b]{2}{*}{ نواحى بدن } \\
\hline (درصد) & معنادارى سطح & 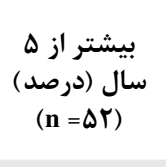 & 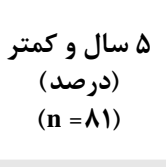 & معنادارى سطح & 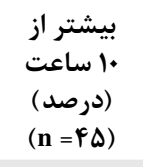 & 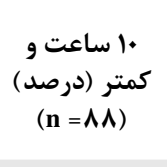 & \\
\hline / & $<\cdot|\cdot \cdot|$ & $\mu \mathcal{F}(\Phi \Delta / r)$ & $1 \cdot(\mid K / T)$ & $<\cdot / \cdot \bullet$ & $\mu_{1}(9 N / \Lambda)$ & $\|(\mid F / V)$ & تردن \\
\hline $11 / r$ & $\cdot 1 \cdot 1$ & $q(I V / T)$ & $\varphi(V / \mathcal{F})$ & $\cdot / r \Delta$ & $V(\mid \Delta / \Delta \Delta)$ & $\wedge(9 / \cdot 9)$ & شانه ها \\
\hline 4 & .110 & $\Delta(9 / 9)$ & $r(r / V)$ & $\cdot / r$ & $f(\Lambda / \Lambda)$ & $f(F / \Delta)$ & آرنج ها \\
\hline 11 & $<\cdot 1 \cdot \cdot 1$ & $11(r F / 9)$ & $\varphi(V / F)$ & $\cdot / r$ & $\mathbb{I}(\mathrm{rN} / \Lambda)$ & $11(1 Y / Q)$ & مج دست /دست \\
\hline $8 / \Lambda$ & $\cdot 1 \cdot 1$ & $9(1 / / 0)$ & $r(r / v)$ & $\cdot / 10$ & $\Delta(11)$ & $f(F / \Delta)$ & يشت \\
\hline$F T / l$ & $<\cdot|\cdot \cdot|$ & $\operatorname{Rr}(\Lambda T / 99)$ & $\mid r(|\varepsilon| \cdot f)$ & $<\cdot|\cdot \cdot|$ & r $(\Lambda \mathcal{F} / \mathcal{F})$ & $\| \Lambda(Y \cdot / \Psi)$ & كمر \\
\hline$\% .9$ & $\cdot 10$ & $f(V / Q)$ & $f(F / q)$ & $\cdot / \cdot 1$ & $\Delta(11 / 1)$ & $r(r / \mathcal{T})$ & زانو ها \\
\hline
\end{tabular}


در افرادى كه داراى سابقه كار بيشتر از ه سال هستند نسبت ه سال بود. هيج كدام از متغيرها با وقوع علائم در نواحى آرنج،

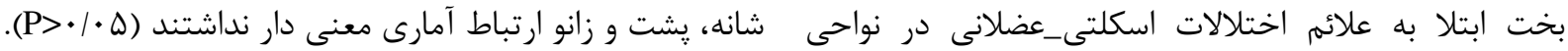

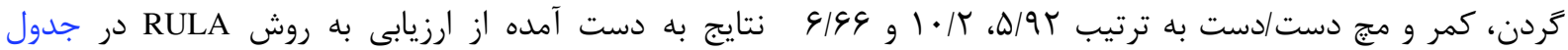

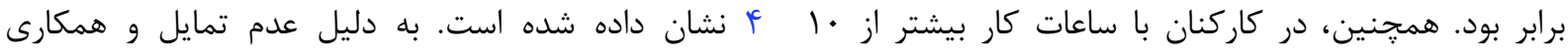

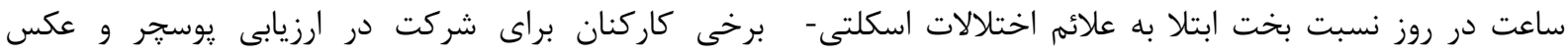

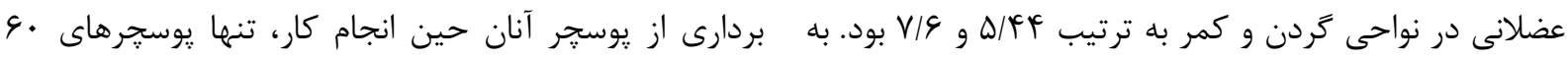

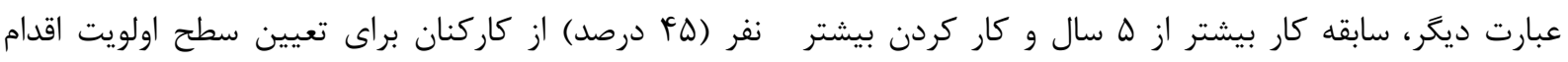

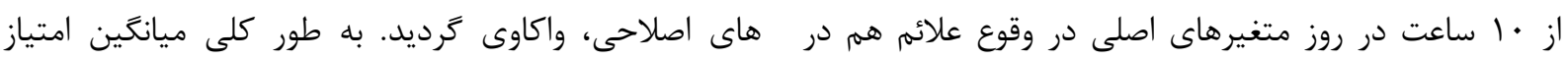

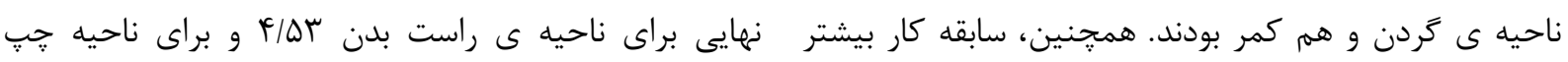

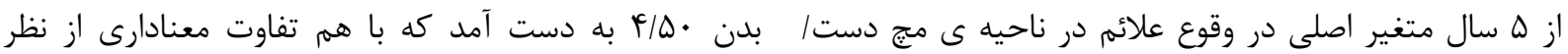

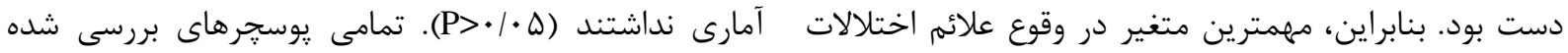
اسكلتى_عضلانى در جمعيت مورد مطالعه سابقه كار بيشتر از كاركنان در سطح اولويت اقدام هاى اصلاحى r و ب هستند.

\begin{tabular}{|c|c|c|c|c|}
\hline \multirow[b]{2}{*}{ سطح معنادارى } & \multicolumn{3}{|c|}{ متغيرهاى باقى مانده در مدل } & \multirow{2}{*}{ 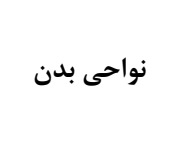 } \\
\hline & $\% 9 \Delta \mathrm{CI}$ & $* \mathbf{O R}$ & متغير ها & \\
\hline$<\cdot / \cdot \cdot \mid$ & $T / 1-19 / 9$ & D/9T & سابقه كار بيشتر از ه سال & \multirow[b]{2}{*}{ 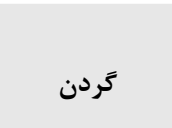 } \\
\hline$<\cdot / \cdot \cdot 1$ & $1 / 9 \Delta-1 \Delta / r$ & $\Delta / F \varphi$ & ساعات كار در روز بيشتر از • ساعت & \\
\hline$<\cdot / \cdot r$ & I/QY - & 9199 & سابقه كار بيشتر از ه سال & مج دست/دست \\
\hline$<\cdot / \cdot \cdots 1$ & $r / 9-r \Lambda$ & $1 \cdot / 4$ & سابقه كار بيشتر از ه سال & \multirow[b]{2}{*}{ 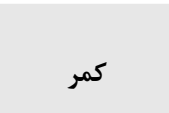 } \\
\hline$<\cdot / \cdot 1$ & $r / D-r r$ & $V / 9$ & ساعات كار در روز بيشتر از • ا ساعت & \\
\hline
\end{tabular}

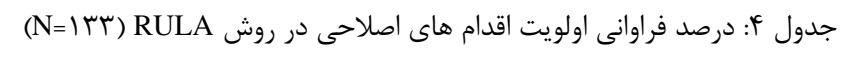

\begin{tabular}{|c|c|c|c|}
\hline \multicolumn{2}{|c|}{ كاركنان } & \multirow{2}{*}{ تعريف } & \multirow{2}{*}{ 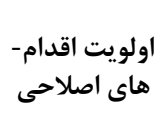 } \\
\hline جֶ & راست & & \\
\hline · & · & قابل قبول & 1 \\
\hline 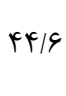 & $F r / l$ & مطالعه فزونتر و ايجاد تغييرات و مداخله ى & $r$ \\
\hline$F \Delta / T^{\epsilon}$ & $F V / q$ & مطاركونوميك فزونتر و آيجاد تغييرات و منديك ضرورى اسله & $r$ \\
\hline • & $\cdot$ & مطالعه فزونتر و ايجاد تغييرات و مداخله ى فرورى استو & $F$ \\
\hline
\end{tabular}


نقش و اثر مدت زمان مواجهه با ريسك فاكتورهاى اختلالات اسكلتى-عضلانى است به اين معنا كه با افزايش مدت زمان مواجهه با اين ريسك فاكتورها احتمال وقوع علائم نيز افزايش

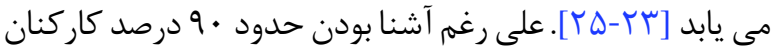
با اركونومى و اصول آن در محيط هاى كار دفترى، حدود r r درصد آنان اظهار داشته اند كه به دليل علائم اختلالات اسكلتى_عضلانى در طول يك سال كذشته به يزشك مراجعه كرده اند و به طور كلى اسكلتى_عضلانى از مشكلات عمده در محيط هاى كار هستند

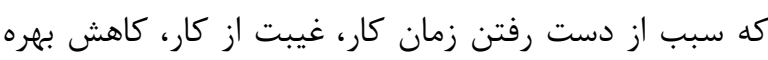
ورى كاركنان و افزايش هزينه هاى توليد و خدمات مى كردد

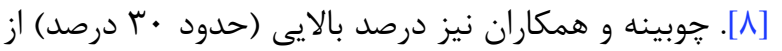
مراجعه ى كاركنان دفترى به مراكز درمانى و غيبت از كار را به دليل آسيب هاى اسكلتى_عضلانى كزارش كرده اند [9].

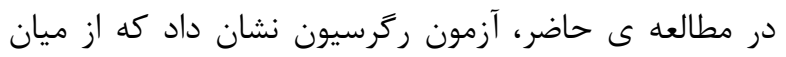

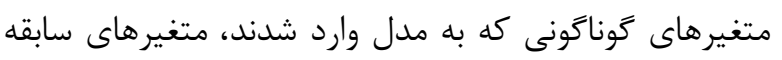

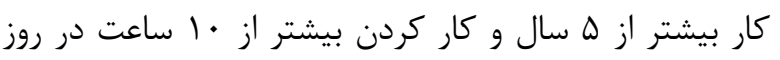

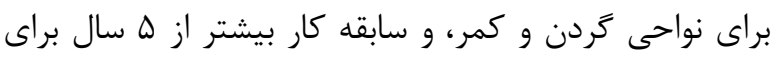
ناحيه ى مج دست/دست به عنوان متغيرهاى موثر در مدل باقى

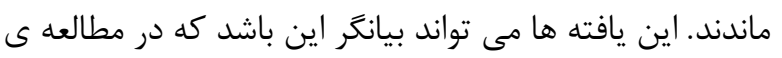
حاضر رابطه مى مشاهده شده بين شيوع اختلالات در سيستم اسكلتى_عضلانى و متغيرهاى مورد مطالعه كه در آزمون هاى مشخص شده اند ناشى از عوامل مخدوش كننده بوده

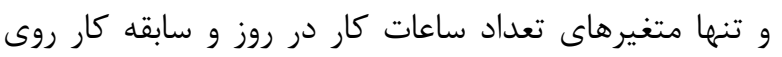

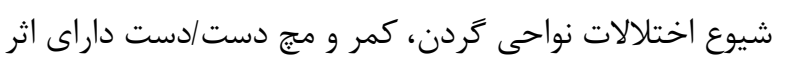

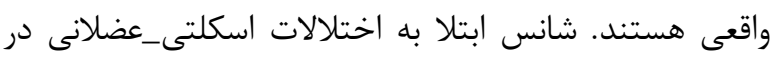

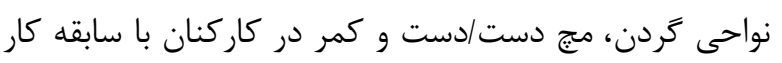
بيشتر از ه سال به ترتيب حدود 9، ه/9 و • أبرابر كاركنانى است كه سابقه كار كمتر از ه سال دارند. به همين ترتيب

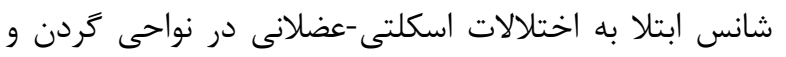

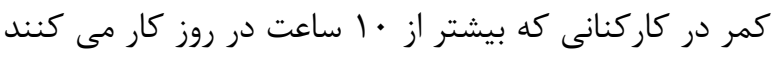

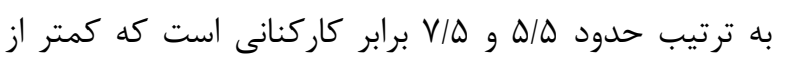

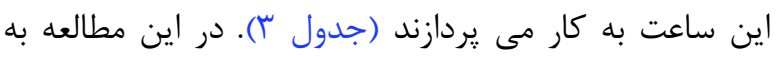

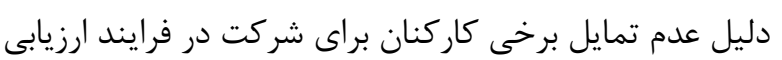
در مطالعه حاضر شيوع علائم اختلالات اسكلتى_عضلانى طى r إه كذشته و ارزيابى ريسك اين اختلالات در كاركنان دفترى بررسى شد. هيج كدام از كاركنان مورد مطالعه سابقه

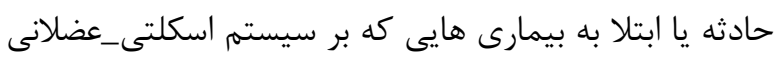
تاثير گذار بوده باشد را كزارش نكردند. نتايج نشان داد كه شيوع

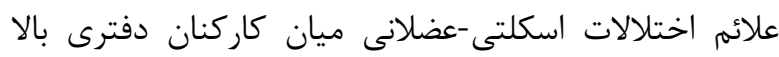

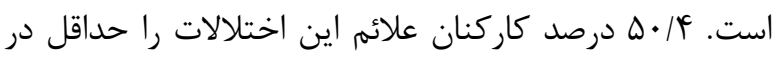

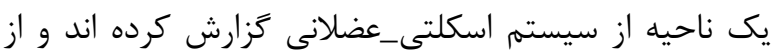

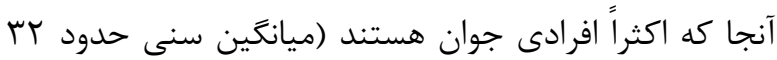
سال) مى تواند بيانكر اين باشد كه مشكلات مربوط به سيستم اسكلتى-عضلانى در اين شغل قابل توجه بوده و كاركنان دفترى در معرض ريسك بالاى ابتلا به اين اختلالات هستند،

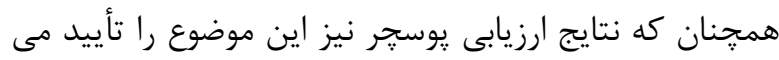

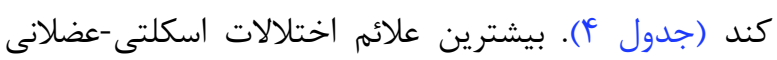

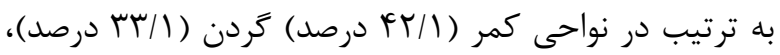

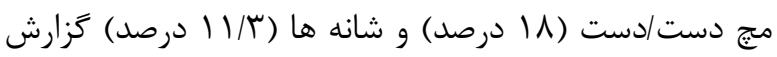
شدند كه با نتايج محققين ديغر (1)، 9، 9 (19 (1) همخوانى دارد.

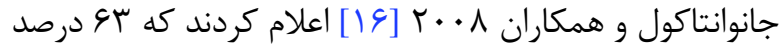
كاركنان دفترى احساس درد و نار احتى را حداقل در يك ناحيه از سيستم اسكلتى-عضلانى كزارش كرده اند و شايع ترين نواحى دركير به ترتيب كردن (YF درصد)، كمر (FF د درصد)،

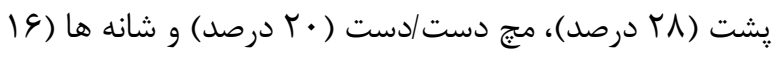

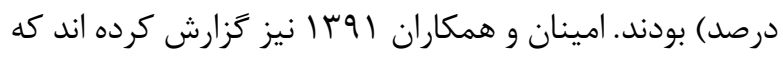

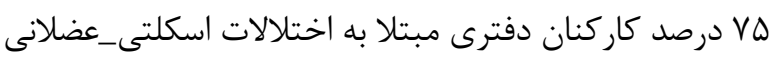
بوده و كمر (ه/ه درصد)، يشت (r/

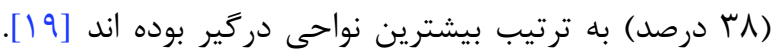
جوبينه و همكاران ا9جا نيز شيوع بالايى از علائم اختلالات اسكلتى_عضلانى در كاركنان دفترى را تزارش كرده اند [9]. در مطالعه ى حاضر، شيوع علائم اختلالات اسكلتى_عضلانى در

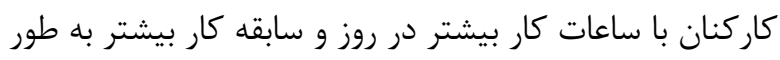

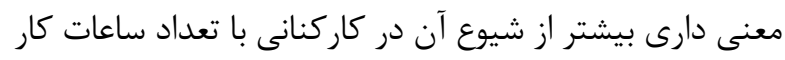

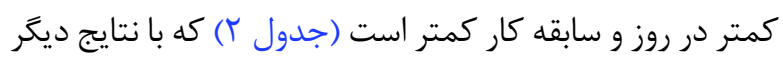

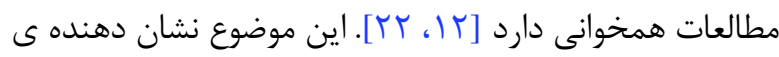




\section{نتيجه كيرى}

يافته هاى مطالعه حاضر نشان مى دهى دهد كه شيوع علائم

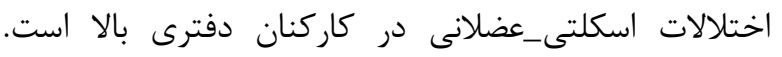

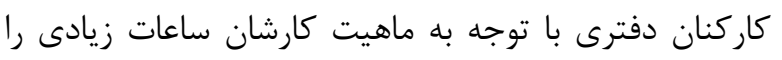

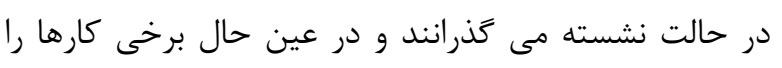

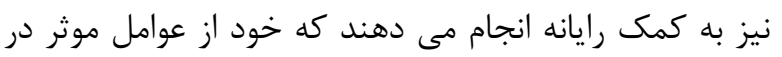
شيوع اين اختلالات مى باشد. سابقه كار بالا و تعداد ساعات

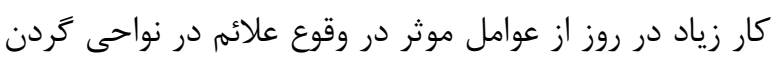

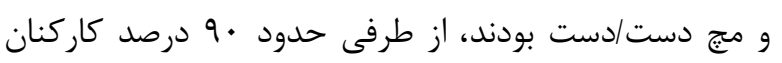
در مطالعه ى حاضر با اركونومى و نقش آن در سلامتشان آشنا

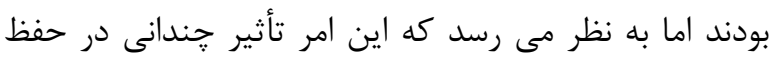

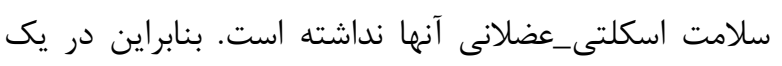
برنامه ى آموزشى مناسب مى بايست اين امر مورد توجه ويز إنها

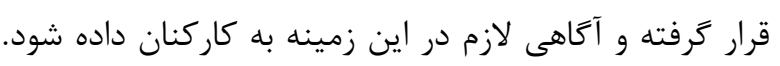

\section{تقدير و تشكر}

مولفين اين مقاله از تمامى كاركنان شركت كنئده در مطالعه و همكارى آنان كمال تشكر ران ماركين دارند. اين

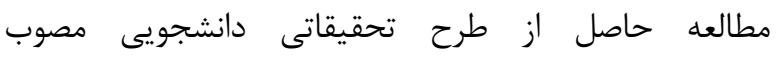

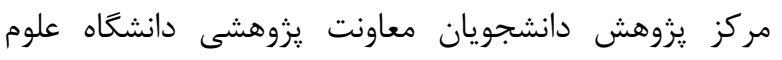

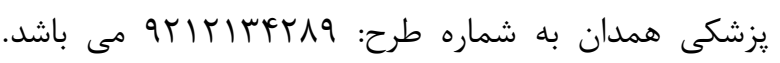

تضاد منافع اين مطالعه براى نويسند كان هيج كَونه تضاد منافعى نداشته
يوسجر امكان واكاوى يوسجر تمامى آنان فراهم نشد. با اين

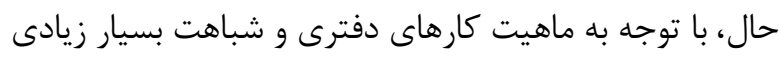

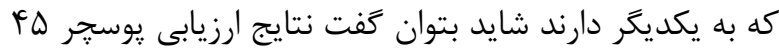

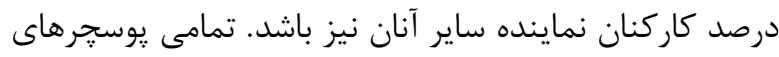

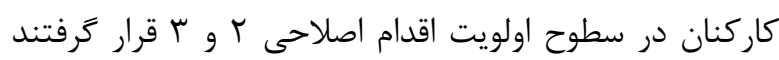

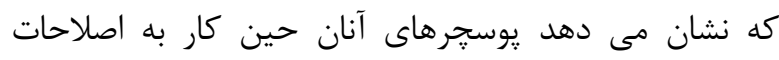
نياز داشته و ايجاد تغييرات و مداخله لى اركونوميك در در آينده

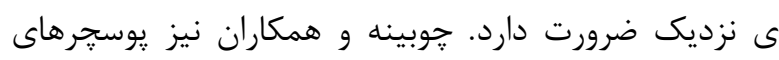

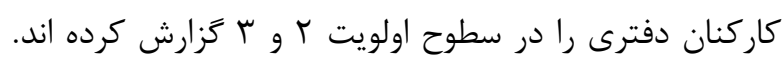

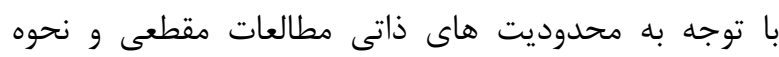
كردآورى داده ها كه خود اظهارى بوده اند، در تفسير يافته دانه

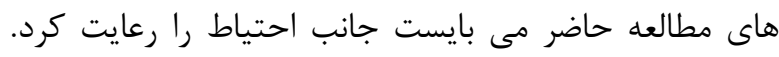

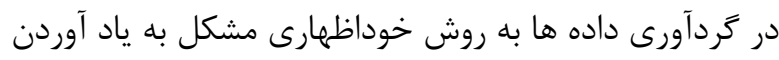

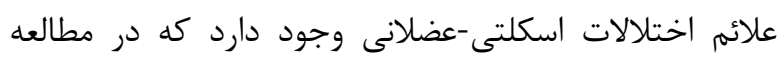

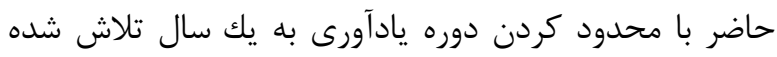

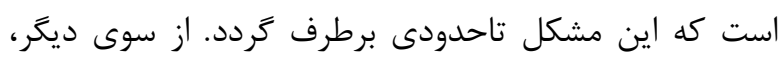

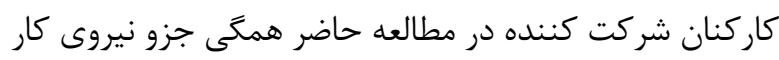

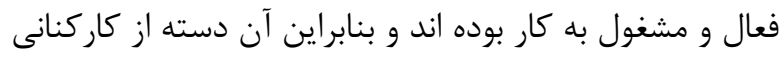

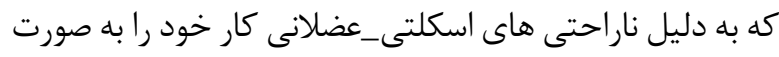

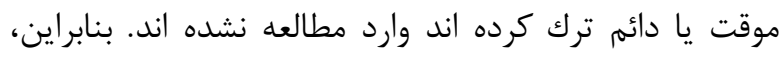

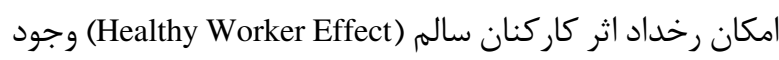

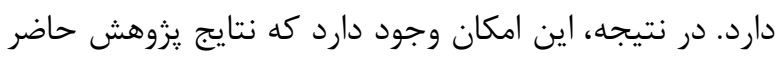

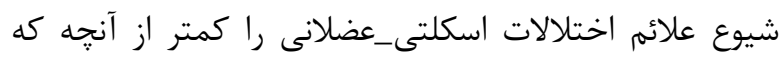

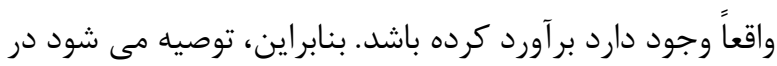
تفسير يافته هاى مطالعه حاضر اين موارد مورد توجه قرار كيرند.

3. Dempsey PG, Burdorf A, Webster BS. The influence of personal variables on work-related lowback disorders and implications for future research. Journal of Occupational and Environmental Medicine. 1997;39(8):748-759.

4. Burdorf A, Sorock GS. Positive and negative evidence 


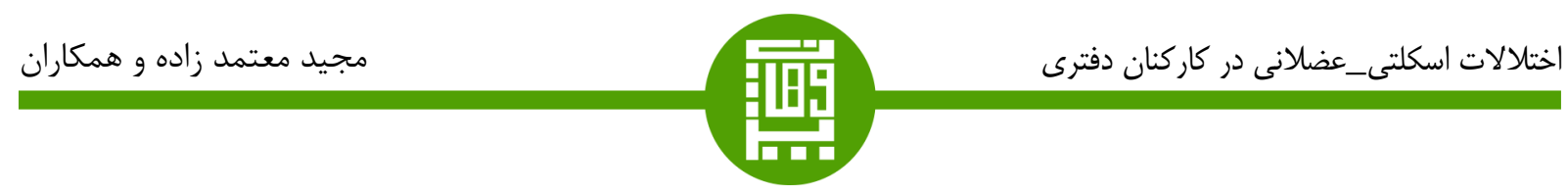

of risk factors for back disorders. Scandinavian journal of work, environment \& health. 1997;23(4):243-256.

5. Kournika I, Forcier L. Work related musculoskeletal disorders: A reference book for prevention. Landon:Taylor and Francis; 1995.

7. Marcello Melis, Youssef S. Abou-Atme, Luca Cottogno, Roberta Pittau. Upper body musculoskeletal symptoms in Sardinian dental students. Journal of the Canadian Dental Association. 2004;70(5):306-310.

8. Choobineh A, Solaymani E, Mohammad Beigi A. Musculoskeletal symptoms among workers of metal structure manufacturing industry in Shiraz, 2005. Iranian Journal of Epidemiology. 2009;5(3):35-43

9. Choobineh A, Rahimifard H, Jahangiri M, Mahmoodkhani S. Musculoskeletal injuries and their associated risk factors in office workplaces. Iran Occupational Health. 2012;8(4):70-80. (Persian)

10. Habibi E, SourySh, Abolghasemi M. The effect of three ergonomics interventions on work-related posture and musculoskeletal disorders in office workers (computer users) Gas Company of Isfahan. Journal of Health System Research. 2013;9(8):1041-1049. (Persian)

11. Wahlstrom J. Ergonomics, musculoskeletal disorders and computer work. Occupational Medicine. 2005;55(3):168-176.

12. Blatter BM, Bongers PM. Duration of computer use and mouse use in relation to musculoskeletal disorders of neck or upper limb. International Journal of Industrial Ergonomics. 2002;30(4):295-306.

13. Ortiz-Herna'ndez L, Tamez-Gonza'lez S Martı'nez-Alca'ntara S, Me'ndez-Ramı'rez I Computer use increases the risk of musculoskeletal disorders among newspaper office workers. Archives of Medical Research. 2003;34(4):331-342.

14. Sharan D, Parijat P, Sasidharan AP, et al. Workstyle risk factors for work related musculoskeletal symptoms among computer professionals in India. Journal of Occupational Rehabilitation. 2011;21(4):520-525.

15. Feldman DE, Shrier I, Rossignol M, Abenhaim L. Work is a risk factor for adolescent musculoskeletal pain. Journal of Occupational and Environmental Medicine. 2002;44(10):956-961.

16. Janwantanakul P, Pensri P, Jiamjarasrangsri V, Sinsongsook T. Prevalence of self-reported musculoskeletal symptoms among office workers. Occupational Medicine. 2008;58(6):436-438.

17. Cook C, Burgess-Limerick R, Chang S. The prevalence of neck and upper extremity musculoskeletal symptoms in computer mouse users. International Journal of Industrial Ergonomics. 2000;26(3):347-356.

18. Korhonen T, Ketola R, Toivonen R, Luukkonen R, Ha“kka“nen M, Viikari-Juntura E. Work related and individual predictors for incident neck pain among office employees working with video display units. Occupational and Environmental Medicine. 2003;60(7):475-482.

19. Aminian O, Pouryaghoub GH, Shanbeh M. One year study of musculoskeletal disorders and their relation to occupational stress among office workers: a brief report. Tehran University Medical Journal. 2012;70(3):194-199. (Persian)

20. Kuorinka I, Jonsson B, Kilbom A, et al. Standardized Nordic Questionnaire for the analysis of musculoskeletal symptom. Applied Ergonomics. 1987;18(3):233-237.

21. Choobineh AR, Lahmi MA, Shahnavaz H, . KhaniJazani R, Hosseini M. Musculoskeletal symptoms as related to ergonomic factors in Iranian hand-woven industry and general guidelines for workstation design. The International Journal of Occupational Safety and Ergonomics. 2004;10(2):157-168. (Persian) 


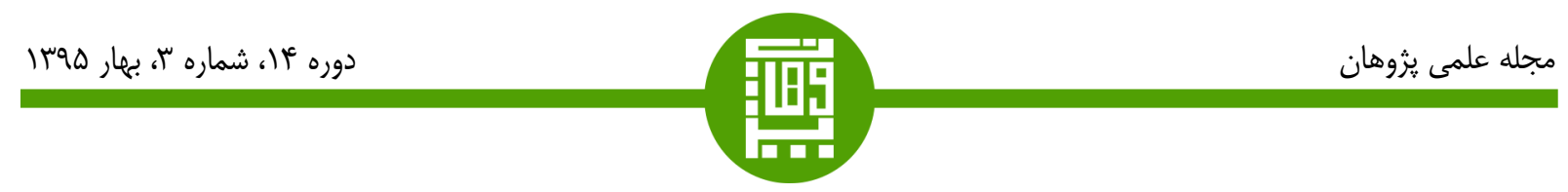

22. Mcatamney L, Corlett E. RULA: A survey method structure manufacturing Industry. Iranian Journal of for the investigation of work related upper limb Epidemiology 2009;5(3):41-49. (Persian) disorders. Applied Ergonomics. 1995;24(2):91-99. 25. Choobineh A, Soleimani E, Daneshmandi 23. Valachi B, Valachi K. Mechanisms leading to H, Mohamadbeigi A, Izadi KH. Prevalence of musculoskeletal disorders in dentistry. The Journal of the musculoskeletal disorders and posture analysis using American Dental Association. 2003;134(10):1344-1350 RULA method in Shiraz general dentists in 2010. 24. Choobineh A, Soleimani E, Mohamadbeigi A. The Journal of Islamic Dental Association of Iran. Musculoskeletal symptoms among workers of metal 2012;24(4):244-250. (Persian) 


\title{
Prevalence and risk assessment of musculoskeletal disorders in office workers of a construction company by $R U L A$ method in 2014
}

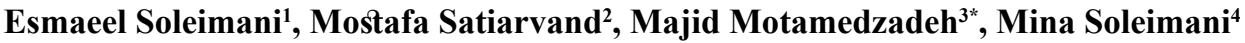 \\ 1 Ph.D. Student of Occupational Health, Student Research Center, Hamadan University of Medical Sciences, Hamadan, Iran \\ 2 MSc Student of Occupational Health, Department of Occupational Health, Shiraz University of Medical Sciences, Shiraz, Iran \\ 3 Professor of Ergonomics, Department of Ergonomics, School of Public Health, Hamadan University of Medical Sciences, Hamadan, Iran \\ 4 BSc Student of Occupational Health, Student Research Center, Hamadan University of Medical Sciences, Hamadan, Iran
}

\section{Aftiels Infor}

Recieved: 11 Apr. 2016

Accepted: 30 May 2016

\section{Keywords}

Musculoskeletal disorders

Prevalence

RULA

Office workers

\section{Corerponding huthor}

Majid Motamedzadeh, Professor of Ergonomic, Department of Ergonomics, School of Public Health, Hamadan University of Medical Sciences, Hamadan, Iran

Tel: +988138381643

Email: Motamedzade@Umsha.ac.ir

\section{Citation}

Soleimani E, Satiarvand M, Motamedzadeh M, Soleimani M. [Prevalence and risk assessment of musculoskeletal disorders in office workers of a construction company by RULA method in 2014]. Pajouhan Scientific Journal. 2016;14(3):39-48

\section{a b s l c a o :}

Introduction: Musculoskeletal disorders (MSDs) are one of the main problems in workplaces, which cause loss of working time, absenteeism, reduced workers' efficiency and increased service and production costs. The present study was carried out to investigate the prevalence of musculoskeletal disorders and their associated risk among office workers.

Methods: In this descriptive cross-sectional study one hundred and thirty three office workers of a huge construction company were involved. For collecting data related to musculoskeletal symptoms and to investigate the associated risk of these disorders the Nordic standard questionnaire and RULA method were used, respectively. Data were analyzed with chi-square test and multiple regressions by using SPSS software version 16.

Results: About $50 \%$ of the workers reported MSDs' symptoms, during the past 12 months, at least in one region of musculoskeletal system. The highest prevalence belonged to lower back (42.1\%), neck (33.1\%), wrist (18\%), and shoulders $(11.3 \%)$, respectively. The prevalence of symptoms in the neck and lower back of workers, with more than 10 working hours per day, was statistically significant $(\mathrm{P}>0.001)$. Additionally, a statistically higher prevalence of symptoms in the neck, wrist, and lower back of workers with job tenure higher than 5 years was noted $(\mathrm{P}>0.05)$. The risk assessment revealed that all workers' postures were fall into action levels of 2 and 3.

Conclusions: The findings revealed that MSDs symptoms have a high prevalence in office workers and the risk of these disorders is intermediate to high. Moreover, the main effective factors in the prevalence of MSDs symptoms were job tenure higher than 5 years and working hours more than 10 per day. 